\title{
NEW QUANTITATIVE ANALYSIS OF CONTRIBUTING FACTORS TO STRENGTH OF DISK SUPERALLOYS
}

\author{
Toshio Osada ${ }^{1,2}$, Yuefeng $\mathrm{Gu}^{1}$, Nobuo Nagashima ${ }^{1}$, Yong Yuan ${ }^{1}$, Tadaharu Yokokawa ${ }^{1}$ and Hiroshi Harada ${ }^{1}$ \\ ${ }^{1}$ National Institute for Materials Science, 1-2-1 Sengen, Tsukuba Science City, Ibaraki 305-0047, Japan \\ ${ }^{2}$ Present address: Yokohama National University, 79-5 Tokiwadai, Hodogaya, Yokohama 240-8501, Japan
}

Keywords: Ni-Co-base superalloy, Hardness, Strengthening, Microstructure, Disk

\begin{abstract}
The contributions of multiple strengthening factors to the $0.2 \%$ flow stress have been studied in a cast and wrought Ni-Co base disk superalloy with varying grain size, twin fraction and bimodal or trimodal $\gamma^{\prime}$ size distributions. The alloy was heat-treated within the $\gamma^{\prime}$ sub- and super-solvus temperature ranges between $1100^{\circ} \mathrm{C}$ to $1180^{\circ} \mathrm{C}$, followed by two step aging heat-treatment. The contribution of each strengthening factor are analyzed by measuring its Vickers hardness at over a structural scale ranging from nano to micro levels and then by converting the hardness differences to the contribution to the $0.2 \%$ flow stress on the basis of the empirical relation: $\sigma_{0.2}=2.46 \mathrm{Hv}$. The results clearly show that the contribution of grain boundary strengthening decreased and reached zero with increasing solution temperature. The behavior followed Hall-Petch effect and Zener's pinning model, and strongly depended on the size and volume fraction of pinning primary $\gamma^{\prime}$ that is un-dissolved during solution treatment. Meanwhile, the contributions of secondary and tertiary $\gamma^{\prime}$ precipitation strengthening increased with increasing temperature. The behaviors also strongly depend on the volume fraction of the primary $\gamma^{\prime}$ since the designed total volume fraction of $\gamma^{\prime}$ of the alloy is approximately 0.5 . As a result, the combinations of these strengthening factors lead to the maximum flow stress at solution temperature of $1135^{\circ} \mathrm{C}$. This would suggest that the primary $\gamma^{\prime}$ plays an important role to optimize the microstructure combination through the solution heat-treatment.
\end{abstract}

\section{Introduction}

Polycrystalline Ni-base disk superalloys with $\gamma / \gamma^{\prime}$ two-phase structure are widely used as turbine disk materials in advanced aircraft engines and land-base gas turbine owing to excellent tensile strength and creep properties [1]. These properties were developed through multiple-strengthening factors. Tensile properties, especially, yield stress $\sigma_{\mathrm{y}}$ may be developed through the solid solution strengthening, precipitation strengthening: primary $\gamma^{\prime}(1-3 \mu \mathrm{m})$, secondary $\gamma^{\prime}(50-300 \mathrm{~nm})$ and tertiary $\gamma^{\prime}(5-$ $50 \mathrm{~nm}$ ), and grain boundary strengthening [2-4]. Additionally, strengthening due to annealing twin boundary will operate in latest Ni-Co-base disk superalloy (TMW®alloy) [5] with low stacking fault energy [6-7]. However, the contribution of each strengthening factor to the total strength of the alloys has not been clearly understood because their complicated microstructure makes it difficult to separately measure the contribution. Thus, it would be time consuming to explore the optimum combination of strengthening factors and their heat-treatment steps.

There have been several attempts to model the contribution of each strengthening factor to the total strength of a typical polycrystalline Ni-base superalloy [4, 8-9]. However, most of these models have been consistently constructed using quantitative calculations with limited experimental results $[4,8]$ or using alloys with simple microstructures [9]. Therefore, these models cannot divide or indicate clearly the contribution of each factor to the total strength. Thus, quantitative analysis of multiplestrengthening factors contributing to total tensile properties is of key importance for optimization of their microstructure and maximization of their mechanical properties through processing.

An indentation test is one of the most common techniques used to extract the local material properties at the nano-, sub-micron-, and micron-scale [10-12]. In particular, nanoindentation combined with atomic force microscopy (AFM) is useful for evaluating the hardness of a specific nanoscale site in a material having complex microstructures, because an in-situ AFM image enables the accurate setting of a Berkovich indenter with a triangular pyramidal shape at the desired site [11]. Furthermore, recently we have proposed a new method for measurement of Vickers hardness values in scales ranging from nano to micro levels in disk superalloy [13], making it possible to divide clearly the each strengthening factors.

The purpose of this study is to clarify the contribution of each strengthening factors to the strength in the Ni-Co-base disk superalloy TMW-4M3 heat-treated at different solution temperatures, and to discuss optimum microstructure combination to get higher strength.

\section{Experimental}

The Ni-Co base disk superalloy, TMW-4M3, used in this study was cut from pancake-shaped disks forged by Mitsubishi Materials Co. Ltd. The chemical compositions of TMW-4M3, the $\gamma^{\prime}$ solvus temperature, and volume fraction calculated using Thermo-Calc. are listed in table I. The material fabrication processes have been described in detail elsewhere [2-3], and the processes for TMW-4M3 are outlined briefly here. Ingots with a diameter of $\phi 500 \mathrm{~mm}$ were prepared by triple melting. The ingots were forged at $1100^{\circ} \mathrm{C}$ into $\phi 200 \mathrm{~mm}$ billets. The billets were then isothermally forged at $1100^{\circ} \mathrm{C}$ into a $\phi 440 \mathrm{~mm}$ pancake-shaped disk. $\phi 10 \mathrm{~mm} \times 70 \mathrm{~mm}$ round bar specimens were cut out of the disk for hardness and tensile testing. For comparison, single crystal bar specimens having a same chemical composition as TMW-4M3 were cast in a NIMS directionally solidification furnace (TMS-4M3). The specimens having $\leq 3^{\circ}$ of $\langle 001\rangle$ orientation to a longitudinal direction were used for hardness and tensile testing.

Heat treatments were carried out at a solution temperature from $1100^{\circ} \mathrm{C}$ to $1180^{\circ} \mathrm{C}$ for $4 \mathrm{~h}$, followed by air cooling (AC). The air- 
Table I Chemical composition, $\gamma^{\prime}$ solvus temperature and volume fraction calculated by Thermo Calc. in TMW-4M3

\begin{tabular}{|c|c|c|c|c|c|c|c|c|c|c|c|c|}
\hline Alloy & Ni & Cr & Co & Mo & W & Ti & Al & C & B & $\mathbf{Z r}$ & $\boldsymbol{\gamma}^{\prime}$ solvus temperature, $\boldsymbol{T}_{\mathbf{s}}{ }^{\circ} \mathbf{C}$ & ${\text { Volume fraction of } \boldsymbol{\gamma}^{\prime}}^{\circ}$ \\
\hline TMW-4M3 & Bal. & 13.5 & 25.0 & 2.8 & 1.20 & 6.20 & 2.30 & 0.03 & 0.02 & 0.03 & $1162^{\circ} \mathrm{C}$ & 0.495 \\
\hline
\end{tabular}

cooled sample was primary aged at $650^{\circ} \mathrm{C} / 24 \mathrm{~h} / \mathrm{AC}$ and then secondary aged at $760^{\circ} \mathrm{C} / 16 \mathrm{~h} / \mathrm{AC}$.

For hardness testing, the heat-treated specimen was cut into a specimen with $\phi 10 \mathrm{~mm} \times 5 \mathrm{~mm}$. The specimens surface were electrolytically polished in a solution of $8 \%$ perchloric acid, $70 \%$ ethanol, $10 \%$ butoxy-ethanol, and $12 \% \mathrm{H}_{2} \mathrm{O}$ at a voltage of $40 \mathrm{~V}$ for $10 \mathrm{~s}$. Ultra-micro- (indentation force: $0.1-1 \mathrm{mN}$ ), micro- (1$1000 \mathrm{mN})$, and Vickers $(0.196-490 \mathrm{mN})$ hardness tests were performed on the polished specimens at room temperature. For the Vickers hardness test, a quadrangular diamond indenter with face angles of $136^{\circ}$ (Akashi) was used. For the micro-hardness test, a triangular pyramidal indenter with an apical angle of $115^{\circ}$ was used. An AFM ultra micro-hardness tester with special levers developed by NIMS was utilized for testing the hardness at the nanoscale level [10-13]. In this study, two types of special levers with apical angles of $60^{\circ}$ and $115^{\circ}$ were used for the triangular pyramidal indenter. Vickers hardness can be calculated based on the indentation force-penetration depth $(F-h)$ curves from the ultra-micro- and micro-hardness tests, and is given by

$H v^{*}=\left\{\frac{F}{p(h+q)^{2}}\right\}^{n}$

where $H v^{*}$ is a converted Vickers hardness and $p, q$, and $n$ are constants. These constants [13] can be estimated empirically from the $F$ - $h$ curves obtained in several single crystals such as those of $\mathrm{Ni}, \mathrm{Mo}$, and $\mathrm{W}$ having a known Vickers hardness. In this study, $F$ - $h$ curves obtained from an ultra-micro-hardness test at $60^{\circ}$, ultramicro-hardness test at $115^{\circ}$, and micro hardness tests, respectively, were used for Vickers hardness conversion. To normalize the difference in shape between pyramidal and Vickers indenters, the size of an indent obtained using the pyramidal indenter is expressed as the square root of the projected area of the triangle indent, $\sqrt{ } S_{0}$

The tensile tests specimens with a gauge section of $22 \mathrm{~mm} \times 4$ $\mathrm{mm}$ were cut out of the bar specimens. Tensile tests were also performed at room temperature with a nominal strain rate of $0.3 \%$ / min.

Structures of the heat-treated alloy were characterized by electron backscatter Diffraction (EBSD) in a field emission scanning electron microscope (FE-SEM), and by transmission electron microscopy (TEM). TEM was performed using a Tecnai TEM operating at $200 \mathrm{kV}$. EBSD were carried out in a JSM-7000F with a field emission gun operating at $20 \mathrm{kV}$ using a program TSL OIM data collection. The grain size $D$ and twin fraction were measured from EBSD data using a program TSL OIM analysis. The $f_{\mathrm{vI}}$ of the primary $\gamma^{\prime}$ precipitation was measured using a point counting method from SEM images. From the TEM images, the average size $d_{\mathrm{II}}, d_{\mathrm{III}}$ and volume fraction $f_{\mathrm{vII}}, f_{\mathrm{vIII}}$ of secondary and tertiary $\gamma^{\prime}$ precipitates were measured using software of NISElements (Nikon).

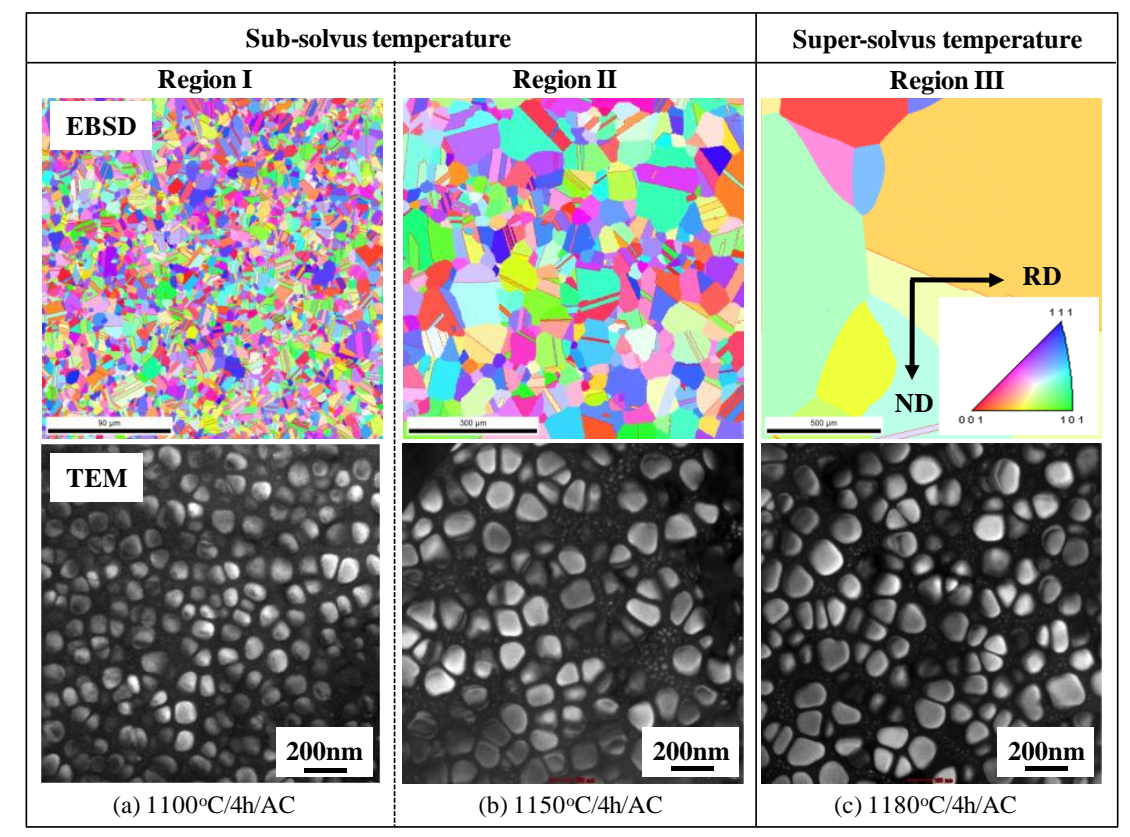

Figure 1 EBSD and TEM dark field images of the alloys solution-heat-treated at (a) $1100^{\circ} \mathrm{C}$, (b) $1150^{\circ} \mathrm{C}$ and (c) $1180^{\circ} \mathrm{C}$ for 4 hours followed by two step aging treatments. (Red line in EBSD images indicate the Annealing twin boundary) 


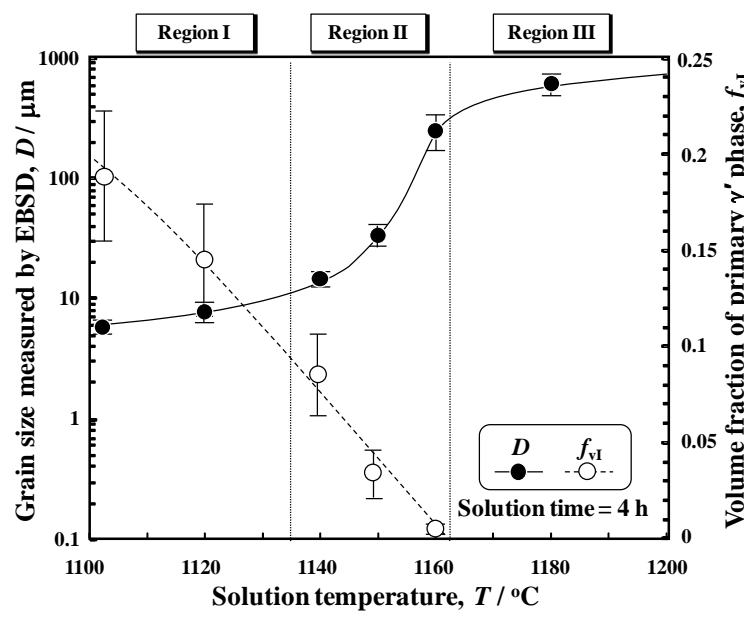

Figure 2 Effect of solution temperature on the grain size $(D)$ and volume fraction $f_{\mathrm{vI}}$ of primary $\gamma^{\prime}$.

\section{Results and discussion}

Microstructure

Figure 1 shows EBSD and TEM dark field images of TMW-4M3 heat-treated at (a) $1100^{\circ} \mathrm{C}$, (b) $1150^{\circ} \mathrm{C}$ and (c) $1180^{\circ} \mathrm{C}$ for 4 hours. The alloy mainly consisted of general grain boundary, annealing twin boundary with $\Sigma 3$, primary $\gamma^{\prime}$, secondary $\gamma^{\prime}$ and tertiary $\gamma^{\prime}$ within the tested solution temperature.

The effect of solution temperature on the grain size $(D)$ and volume fraction $f_{\mathrm{vI}}$ of primary $\gamma^{\prime}$ which were measured from EBSD and SEM images, respectively, are shown in figure 2. The $f_{\mathrm{vI}}$ decreased with increasing the temperature and reached to 0 at $T$ $\approx 1162^{\circ} \mathrm{C}$ for 4 hours. Thus, the $\gamma^{\prime}$ solvus temperature $T_{\mathrm{S}}$ should lie within $1150<T_{\mathrm{S}}<1160$. In this study, we determined the $T_{\mathrm{S}}$ of the alloy heated for 4 hours as $\approx 1162^{\circ} \mathrm{C}$.

Within the $\gamma^{\prime}$ sub-solvus temperature range, the grain size increased slightly from about 6 to $10 \mu \mathrm{m}$ with increasing the temperature from $1100^{\circ} \mathrm{C}$ to $1135^{\circ} \mathrm{C}$ (Region I), and increased significantly from about 10 to $300 \mu \mathrm{m}$ with increasing the temperature from $1135^{\circ} \mathrm{C}$ to $\gamma^{\prime}$ solvus temperature (Region II). This behavior can be explained by Zener's pinning model of the pinning primary $\gamma^{\prime}$ [14-15]. Meanwhile, the fraction of annealing twin boundary increased during the grain growth and reach to 38$43 \%$. Within the $\gamma^{\prime}$ super-solvus temperature range, grain size increased from about 300 to $620 \mu \mathrm{m}$. The grain grew very quickly because the pinning primary $\gamma^{\prime}$ dissolved completely (Region III).

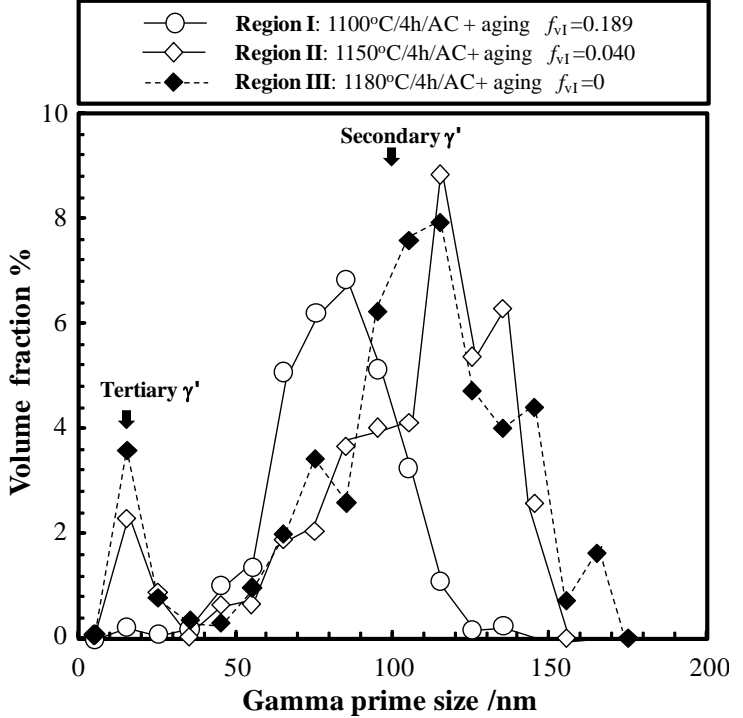

Figure 3 Size distributions of intragranular $\gamma^{\prime}$ precipitates measured from TEM images.

For convenience, we categorized the solution temperature ranges into above three regions according to its growth rate.

The size distributions of intragranular $\gamma^{\prime}$ precipitates measured from TEM images are shown in figure 3. At all the solution temperature, the bimodal distribution can be observed within the grain. Thus, the trimodal and bimodal distributed $\gamma^{\prime}$ are present in the tested alloy heat-treated within the sub-solvus temperature (Region I and II) and super-solvus temperature range (Region III), respectively, considering the present of the primary $\gamma^{\prime}$. With increasing the temperature, both an average size $d_{\mathrm{II}}$ and the volume fraction $f_{\mathrm{VII}}$ of the secondary $\gamma^{\prime}$ gradually increased. Meanwhile, the size $d_{\mathrm{III}}$ of the tertiary $\gamma^{\prime}$ are unaltered, although the volume fraction $f_{\mathrm{vIII}}$ of the tertiary $\gamma^{\prime}$ increased from 0.0019 to 0.05

It should be noted that both the increase in $f_{\mathrm{VII}}$ and $f_{\mathrm{VIII}}$ strongly depends on the decrease in $f_{\mathrm{vI}}$ of the primary $\gamma^{\prime}$ un-dissolved during solution heat-treatment. Furthermore, the total fraction of $\gamma^{\prime}: f_{\mathrm{v}}^{\text {total }}=f_{\mathrm{vI}}+f_{\mathrm{vII}}+f_{\mathrm{vIII}}$ is approximately 0.5 in all the solution temperature, which is almost close to the volume fraction at the second aging temperature of $760^{\circ} \mathrm{C}$ calculated by Thermo Calc. All the microstructural features are listed in table II

Our finding suggested that $D, f_{\mathrm{vII}}$ and $f_{\mathrm{vIII}}$ strongly depend on the $f_{\mathrm{vI}}$. Thus, it is important to understand the solution and coarsening behaviors of the primary $\gamma^{\prime}$ precipitates for controlling the states of microstructure.

Table II Effect of solution temperature on microstructural parameters

\begin{tabular}{|c|c|c|c|c|c|c|c|c|}
\hline \multirow{2}{*}{$\begin{array}{c}\text { Solution } \\
\text { temperature }\end{array}$} & \multirow{2}{*}{$\begin{array}{c}\text { Grain size, } \\
\mathrm{D} / \mu \mathrm{m}\end{array}$} & \multirow{2}{*}{$\begin{array}{c}\text { Twin } \\
\text { fraction }\end{array}$} & \multicolumn{2}{|c|}{ Primary $\gamma^{\prime}$} & \multicolumn{2}{|c|}{ Secondary $\gamma^{\prime}$} & \multicolumn{2}{|c|}{ Tertiary $\gamma^{\prime}$} \\
\hline & & & Volume fraction, $f_{\mathrm{VI}}$ & Size, $d_{\mathrm{I}} / \mu \mathrm{m}$ & Volume fraction, $f_{\mathrm{vII}}$ & Size, $d_{\mathrm{II}} / \mathrm{nm}$ & Volume fraction, $\boldsymbol{f}_{\mathrm{vIII}}$ & Size, $d_{\mathrm{II}} / \mathrm{nm}$ \\
\hline $1100^{\circ} \mathrm{C}$ & $6.00 \pm 0.68$ & 0.382 & 0.189 & $2.65 \pm 0.24$ & 0.304 & $72.87 \pm 17.99$ & 0.0019 & $16.0 \pm 2.66$ \\
\hline $1150^{\circ} \mathrm{C}$ & $60.8 \pm 14.4$ & 0.424 & 0.040 & $2.77 \pm 0.31$ & 0.405 & $93.17 \pm 37.22$ & 0.0331 & $15.1 \pm 4.35$ \\
\hline $1180^{\circ} \mathrm{C}$ & $619 \pm 131$ & 0.249 & - & - & 0.455 & $97.82 \pm 27.25$ & 0.0509 & $15.4 \pm 4.39$ \\
\hline
\end{tabular}


New quantitative analysis of contributing factors

Figure 4 (a), (b) and (c) show the relationship between converted Vickers hardness and indent size in the TMW-4M3 heat-treated at $1100^{\circ} \mathrm{C}$ (Region I), $1150^{\circ} \mathrm{C}$ (Region II) and $1180^{\circ} \mathrm{C}$ (Region III), respectively. For comparison, the hardness of single crystal TMS$4 \mathrm{M} 3$ is also shown in figure 5 (c). The hardness of the pure Ni single crystals (001) is 93, which is used as the hardness of the base materials $\left(H v_{\mathrm{Ni}}\right)$.

The results clearly show that the indent size has a significant influence on the converted Vickers hardness. This means that multiple strengthening factors due to general grain boundary $\Delta H v_{\mathrm{GB}}$, annealing twin boundary $\Delta H v_{\mathrm{TB}}$, primary $\gamma^{\prime} \Delta H v_{\gamma^{\prime} \mathrm{I}}$, secondary $\gamma^{\prime} \Delta H v_{\gamma^{\prime} I I}$, tertiary $\gamma^{\prime} \Delta H v_{\gamma^{\prime} \text { III }}$ together with solid solution $\Delta H v_{\text {sol }}$ may operate hierarchically, depending on the tested range, which is evaluated to the microstructural feature as show in figure 1. It is important to note that the hardness increased significantly from a certain $\sqrt{ } S_{0}$ when the $\sqrt{ } S_{\mathrm{o}}$ increased. This is due to the fact that as the $\sqrt{ } S_{\mathrm{o}}$ exceeds a certain level, the deformed zone around the indents will inevitably successively transcend different microstructure features: secondary $\gamma^{\prime}$, primary $\gamma^{\prime}$, twin boundaries and grain boundaries, leading to the large hardness increments.

The alloys heat-treated at $1100^{\circ} \mathrm{C}$ (Region I) and $1150^{\circ} \mathrm{C}$ (Region II) showed similar hardening behaviors. For the case of $1100^{\circ} \mathrm{C}$ (Region I), the experimental $H v$ had three constant values, 237, 402 , and 474, within the ranges of $\sqrt{ } S_{\mathrm{o}} \leq 150 \mathrm{~nm}, 1 \mu \mathrm{m} \leq \sqrt{ } S_{\mathrm{o}} \leq$ $4 \mu \mathrm{m}$, and $\sqrt{ } S_{\mathrm{o}} \geq 20 \mu \mathrm{m}$, respectively. Thus, the experimental hardness comes from $H v_{\mathrm{Ni}}+\Delta H v_{\mathrm{sol}}+\Delta H v_{\gamma^{\prime} \text { III }}$ in the tested range of $\sqrt{ } S_{\mathrm{o}} \leq 150 \mathrm{~nm} ; H v_{\mathrm{Ni}}+\Delta H v_{\mathrm{sol}}+\Delta H v_{\gamma^{\prime} \text { III }}+\Delta H v_{\gamma^{\prime} \text { II }}$ in the tested range of $1 \mu \mathrm{m} \leq \sqrt{ } S_{0} \leq 4 \mu \mathrm{m}$; and $H v_{\mathrm{Ni}}+\Delta H v_{\text {sol }}+\Delta H v_{\gamma^{\prime} \text { III }}+\Delta H v_{\gamma^{\prime} I I}+\Delta H v_{\gamma^{\prime} \mathrm{I}}$ $+\Delta H v_{\mathrm{GB}}+\Delta H v_{\mathrm{TB}}$ in the tested range of $\sqrt{ } S_{\mathrm{o}} \geq 20 \mu \mathrm{m}$. Therefore, we can obtain 144 for $\Delta H v_{\text {sol }}+\Delta H v_{\gamma^{\prime} \text { III }}, 165$ for $\Delta H v_{\gamma^{\prime} \text { II }}$, and 72 for $\Delta H v_{\gamma^{\prime} \mathrm{I}}+\Delta H v_{\mathrm{GB}}+\Delta H v_{\mathrm{TB}}$ in the Region I. For the case of $1150^{\circ} \mathrm{C}$ (Region II), thus, we also obtain 160 for $\Delta H v_{\text {sol }}+\Delta H v_{\gamma^{\prime} I I I}, 191$ for $\Delta H v_{\gamma^{\prime} \mathrm{II}}$, and 33 for $\Delta H v_{\gamma^{\prime}}+\Delta H v_{\mathrm{GB}}+\Delta H v_{\mathrm{TB}}$. For the case of $1180^{\circ} \mathrm{C}$ (Region II), the experimental $H v$ had only two constant values, 255, and 473, within the ranges of $\sqrt{ } S_{0} \leq 140 \mathrm{~nm}$ and $\sqrt{ } S_{0} \geq$ $7 \mu \mathrm{m}$, respectively. This is due to the fact that since the alloy has no primary $\gamma^{\prime}$ and the large grain $(D=620 \mu \mathrm{m})$, even the large Vickers indent cannot cross the primary $\gamma^{\prime}$ precipitates, grain boundaries and twin boundaries. Thus, we obtain 162 for $\Delta H v_{\text {sol }}+\Delta H v_{\gamma^{\prime} \text { III }}$, and 218 for $\Delta H v_{\gamma^{\prime} \mathrm{II}}$.

Thus, we can concluded that the method presented here can be divided the total hardness $H v_{\text {total }}$ into three hardness increment $\Delta H v$ in addition to the base material hardness, based on the experimental Vickers hardness and its value difference as follow:

$\begin{array}{ll}\text { ( } & H v_{1}=H v_{\mathrm{Ni}} \\ \text { (2) } & \Delta H v_{2}=\Delta H v_{\mathrm{sol}}+\Delta H v_{\gamma^{\prime} \mathrm{III}} \\ \text { (3) } & \Delta H v_{3}=\Delta H v_{\gamma^{\prime} \mathrm{II}} \\ \text { (4 } & \Delta H v_{4}=\Delta H v_{\gamma^{\prime} \mathrm{I}}+\Delta H v_{\mathrm{GB}}+\Delta H v_{\mathrm{TB}}\end{array}$

Here, we should note that the hardening behavior in the alloy heat-treated at $1180^{\circ} \mathrm{C}$ is very similar to that in single crystal TMS-4M3. This result implies that the hardness values obtained here are reasonable. Furthermore, this approach can completely isolate the hardening from the secondary $\gamma^{\prime} \Delta H v_{\gamma^{\prime} I I}$. Thus, we conclude that the new proposed method is very useful to quantitatively measure the contribution of each hardening factor to the total hardness.

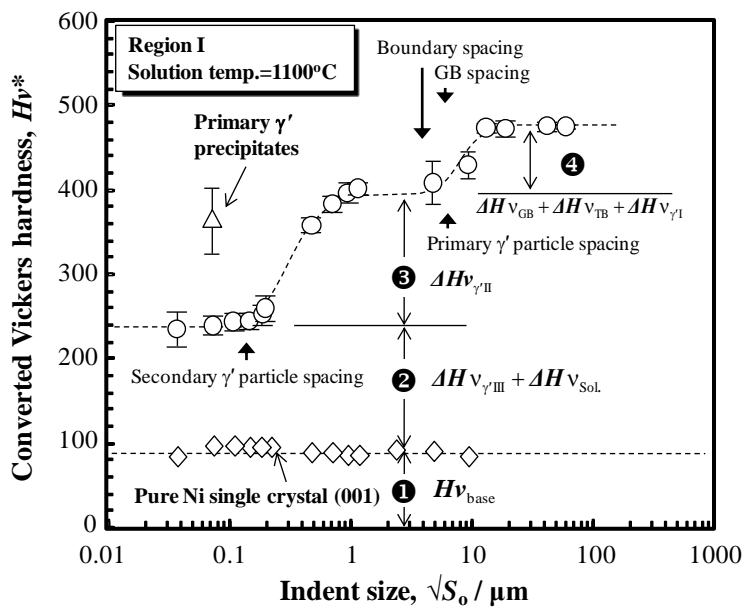

(a) Region I

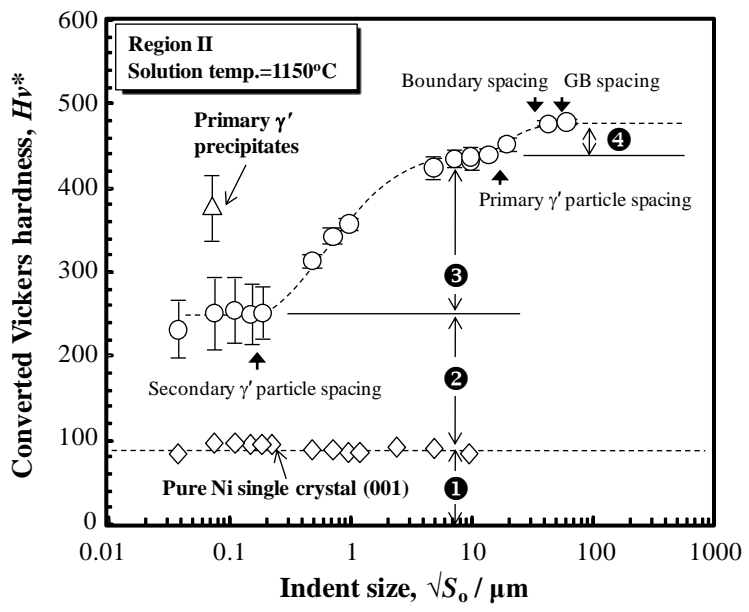

(b) Region II

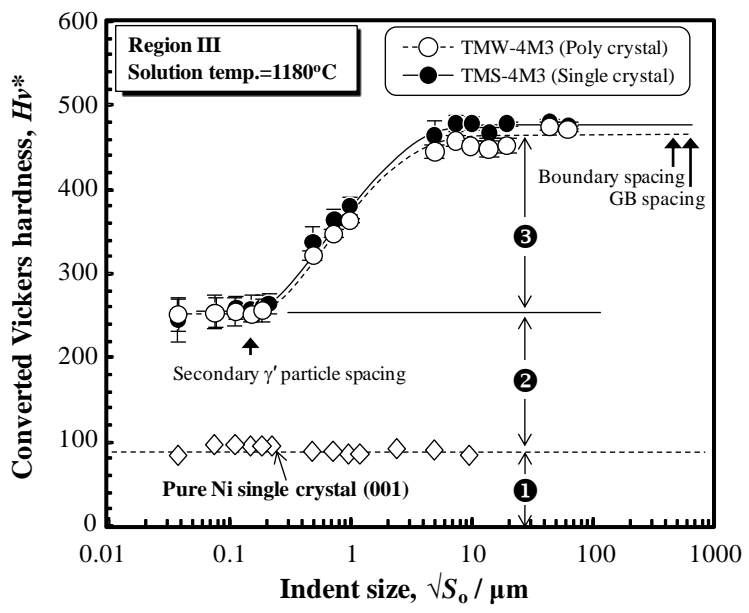

(c) Region III

Figure 4 Relationship between converted Vickers hardness and indent size in alloy solution-heat-treated at (a) Region I: $1100^{\circ} \mathrm{C}$

(b) Region II: $1150^{\circ} \mathrm{C}$ and (c) Region III: $1180^{\circ} \mathrm{C}$ 


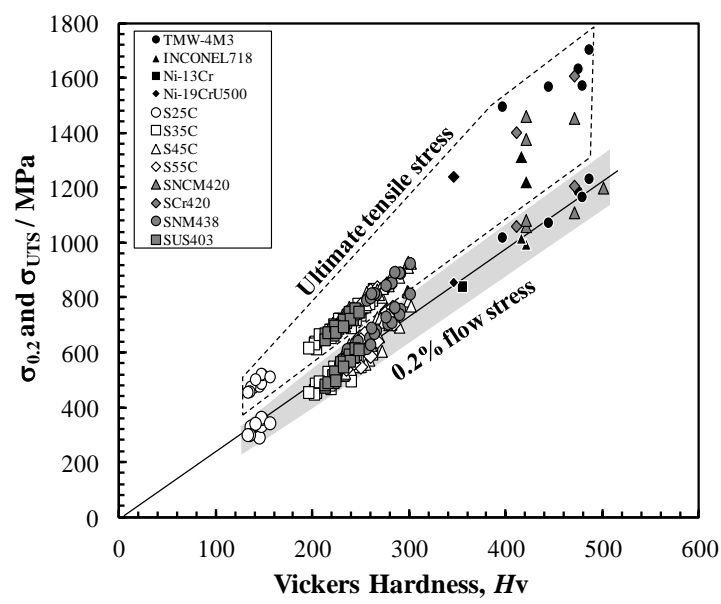

Figure 5 Relationship between $0.2 \%$ flow stress and Vickers hardness in typical metals and alloys [15].

Relationship between total strength and total hardness

The $H v_{\text {total }}$ can be converted to the total tensile strength. It has been reported that ultimate tensile strength $\sigma_{\mathrm{UTS}}$ and $0.2 \%$ flow stress $\sigma_{0.2}$ have linear relation to its Vickers hardness within the $H v$ ranging approximately $100 \leq H v \leq 400$ [16]. However, the converted $H v$ of the tested alloy were distributing within $100 \leq H v$ $\leq 500$. Thus, we discussed the relationship between tensile strength and Vickers hardness for typical metals in addition to the tested alloy as shown in Figure 5. The figure indicates that $H v$ shows a better proportional relationship with the $\sigma_{0.2}$ than the $\sigma_{\text {UTS }}$ Thus, we obtained

$\sigma_{0.2}=2.46 H v_{\text {total }}$

for all metals: steel, stainless steel, Ni-alloy and $\mathrm{Ni}$ base superalloys [16] in addition to the tested alloys. Moreover, the relation could be applied to a wide range of values between $100 \leq$ $H v \leq 500$. Meanwhile, $H v$ also has a proportional relation with $\sigma_{\text {UTS }}$ for each metal, but the slope differs depending on the material. This could be caused by the difference in work hardening behaviors [17].

Strengthening Map

The strengthening behaviors in the alloy system can be described by superposition of each strengthening mechanism. Several models of superposition have been proposed [18]. The general equation is given by:

$\sigma_{\text {total }}^{k}=\sum_{i} \Delta \sigma_{i}^{k}$

where $i$ is number of strengthening mechanism. The exponent $k$ is adjustable parameter, and varies between 1.0 and 2.0 in the actual material. The values have been proposed theoretically $k=1.0$ [18]. Assuming that $k=1[4,19]$, the total strength of the disk alloy can be described by superposition of several strengthening factors as follows:

$\sigma_{0.2}=\sigma_{\mathrm{Ni}}+\Delta \sigma_{\mathrm{sol}}+\Delta \sigma_{\gamma^{\prime} \mathrm{III}}+\Delta \sigma_{\gamma^{\prime} \mathrm{II}}$

$$
+\Delta \sigma_{\gamma^{\prime} \mathrm{I}}+\Delta \sigma_{\mathrm{GB}}+\Delta \sigma_{\mathrm{TB}}
$$

Assuming that the relation: $\sigma_{0.2}=2.46 \mathrm{Hv}$ is still active in all strengthening factors in the tested alloy and within all the tested range, equation [8] can be rewritten as:

$$
\begin{aligned}
\sigma_{0.2}= & 2.46\left(H v_{\mathrm{Ni}}+\Delta H v_{\mathrm{sol}}+\Delta H v_{\gamma^{\prime} \mathrm{III}}+\Delta H v_{\gamma^{\prime} \mathrm{II}}\right. \\
& \left.+\Delta H v_{\gamma^{\prime} \mathrm{I}}+\Delta H v_{\mathrm{GB}}+\Delta H v_{\mathrm{TB}}\right) \\
= & 2.46 H v_{\mathrm{Ni}}+2.46\left(\Delta H v_{\mathrm{sol}}+\Delta H v_{\gamma^{\prime} \mathrm{III}}\right)+2.46 \Delta H v_{\gamma^{\prime} \mathrm{II}} \\
& +2.46\left(\Delta H v_{\gamma^{\prime} \mathrm{I}}+\Delta H v_{\mathrm{GB}}+\Delta H v_{\mathrm{TB}}\right)
\end{aligned}
$$

Thus, substituting the equation [2]-[5] into equation [10], the effect of solution temperature on the individual strengthening mechanism contributing to the $0.2 \%$ flow stress can be summarized as shown in Figure 6.

By using the quantitative analysis proposed here, we can clearly understand the contributions of each of multi-strengthening factors to the $\sigma_{0.2}$. With increasing the solution temperature, the total strength (both the measured and converted $0.2 \%$ flow stress) increased in region I, decreased in region II, and reached to the values obtained from TMS-4M3 in region III. With increasing the solution temperature, $\Delta \sigma_{\gamma^{\prime} \mathrm{T}}+\Delta \sigma_{\mathrm{GB}}+\Delta \sigma_{\mathrm{TB}}$ decreased, which would be mainly explained by Hall-Petch relation [20]: $\Delta \sigma_{\mathrm{GB}}=k_{\mathrm{GB}} / \sqrt{ } D$ and Zener's pinning model of the pinning primary $\gamma^{\prime}$. In region I, $\Delta \sigma_{\mathrm{GB}}$ decreased slightly, because of slight increase of grain size. In region II, $\Delta \sigma_{\mathrm{GB}}$ decreased significantly. This is due to the fact that grain size increased significantly with decreasing the volume fraction of the pinning primary $\gamma^{\prime}$. In region III, $\Delta \sigma_{\mathrm{GB}}$ decreased and reached to $\Delta \sigma_{\mathrm{GB}} \approx 0$, because of large grain size.

Meanwhile, $\Delta \sigma_{\gamma^{\prime} I I}$ increased significantly as the solution temperature increased and showed a maximum value at around $\gamma^{\prime}$ solvus temperature. The increment would be due to the increase in the volume fraction of secondary $\gamma^{\prime}$ precipitates from 0.304 to 0.455 according to a strengthening model for strong coupled pair dislocation [21].

Assuming that solid solution strengthening $\Delta \sigma_{\text {sol }}$ is constant within test temperature ranges since all the alloys eventually heattreated at the same aging temperature, $\Delta \sigma_{\gamma^{\prime} \text { III }}$ also slightly increased with increasing the temperature. This is due to the fact that the tertiary $\gamma^{\prime}$ volume fraction slightly increased from 0.0019 to 0.05 .

As a result, both the converted and measured $0.2 \%$ flow stress showed a maximum value of the strength at the solution temperature between the region I and region II $\left(1135^{\circ} \mathrm{C}\right)$. Thus, we can conclude that the $1135^{\circ} \mathrm{C}$ is optimum solution temperature, which can lead to the optimum combination of microstructure and the strengthening factors contributing to the yield stress at room temperature. Additionally, we should note the role of the $\gamma^{\prime}$ precipitates. Many researchers are not too interest in the precipitates, because of the fact that contribution of the primary $\gamma^{\prime}$ with low $f_{\mathrm{vI}}$ and large particle size to the strength of the disk superalloy at room temperature is very small. However, the finding here clearly indicated that the evolution of primary $\gamma$ controlled the state of other microstructure and their strengthening behaviors. Thus, we can conclude that the understanding evolution of the primary $\gamma^{\prime}$ during the solution-heat-treatment [15] 
is a key to the optimization of microstructure and their multistrengthening behaviors in the disk superalloy.

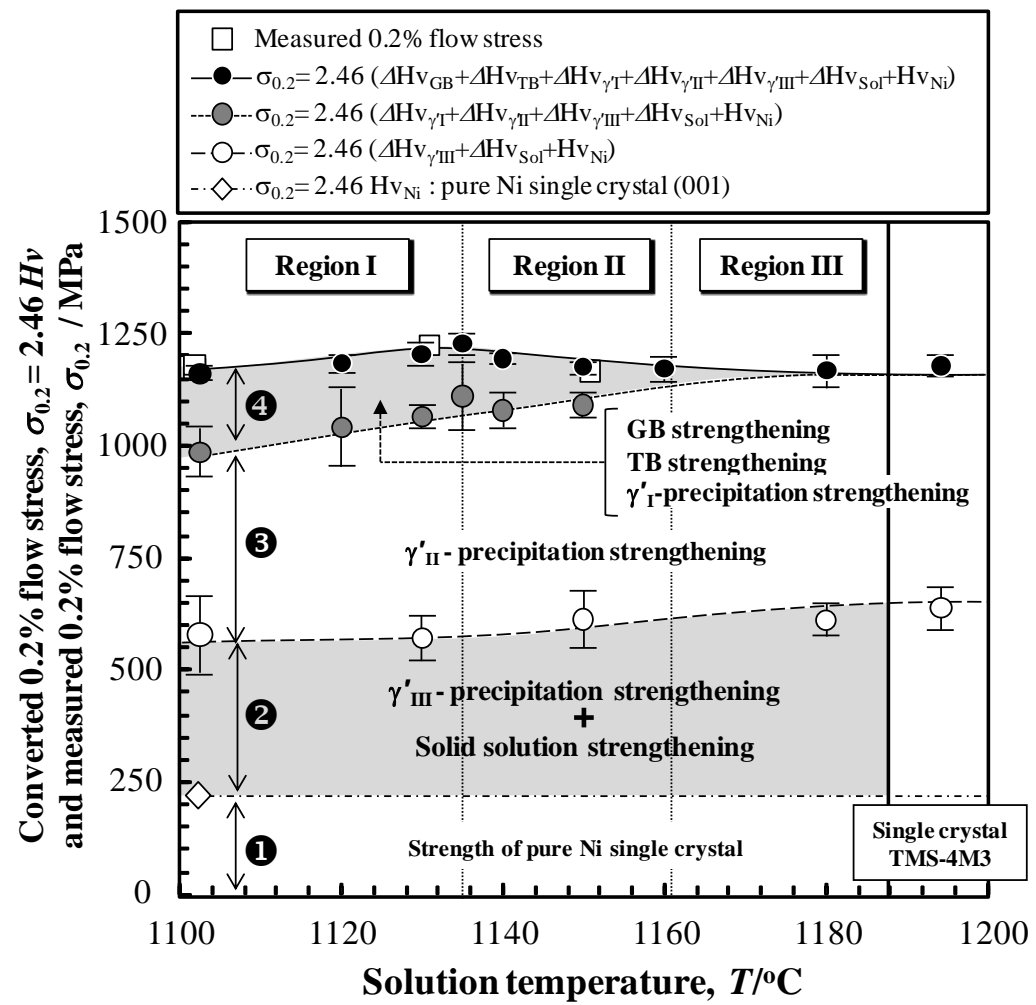

Figure 6 Strengthening map: effect of solution temperature on $0.2 \%$ flow stress and contribution of each strengthening factors.

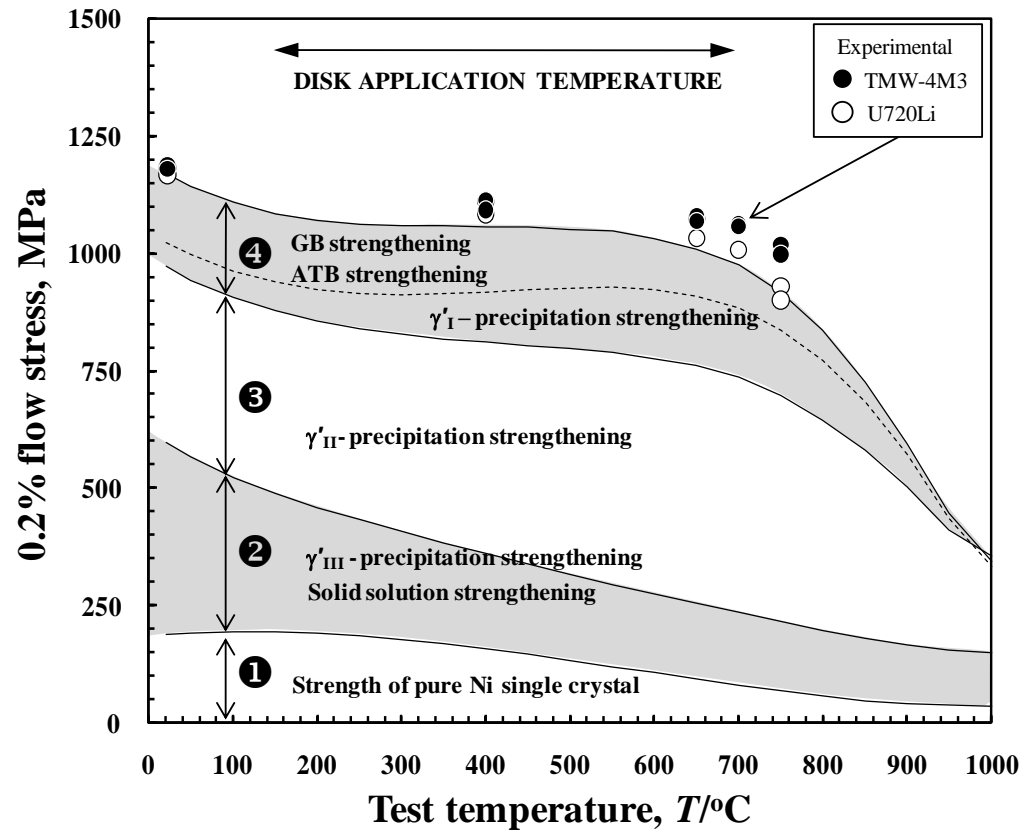

Figure 7 Schematic Illustration: temperature dependence of strengthening factors. 
High temperature strength

This new quantitative method may extend to analyze the tendency of strengthening factors with increasing temperature to real application of turbine disks at high temperature. Figure 7 shows the schematic illustration of temperature dependence of multiplestrengthening factor in the TMW-4M3. As shown in the figure, the contributing factors in TMW-4M3 may be still active below at least $650{ }^{\circ} \mathrm{C}$ because there is little decline in experimental tensile strength from RT to about $650^{\circ} \mathrm{C}$ [2]. Furthermore, this would be also supported by the fact that dislocation activity, involving antiphase boundary (APB), is the dominant tensile mechanism in TME-4M3 up to about $650^{\circ} \mathrm{C}$ [22-23]. According to our findings, we try to illustrate the high temperature strength. For example, $\Delta \sigma_{\mathrm{GB}}$ may exhibit negative temperature dependence because of the degradation of $k_{\mathrm{GB}}$ in Hall-Petch relation. Meanwhile $\Delta \sigma_{\gamma^{\prime I I}}$ may be almost constant or slightly increase. $\Delta \sigma_{\text {sol }}+\Delta \sigma_{\gamma^{\prime} \text { III }}$ will be decrease because $\Delta \sigma_{\text {sol }}$ may decrease with increasing temperature. $\sigma_{\mathrm{Ni}}$ should decrease slightly from RT to about $725^{\circ} \mathrm{C}$.

This approach will be applied to conventional Ni-base superalloys such as U720Li, because the same deformation mechanism as the tested alloy can be observed in $\mathrm{U} 720 \mathrm{Li}$ at high temperature. However, we should be careful about temperature range, because the tensile deformation mechanism in TMW-4M3 transfer from dislocation pairs cutting to stacking fault (SF) shearing and deformation twinning at about $650^{\circ} \mathrm{C}$ [22-23].

Present effort is focused on obtaining contributing strengthening factors at high temperature, then confirming that the method can be used to analyze each strengthening factor from RT to high temperature.

\section{Conclusion}

In this paper, contributions of multiple strengthening factors to the $0.2 \%$ flow stress have been investigated in a cast and wrought NiCo base superalloys heat-treated at different solution-heattreatment conditions. Microstructure observation indicated that the grain size, volume fraction of secondary $\gamma^{\prime}$ and tertiary $\gamma^{\prime}$ strongly depend on that of the un-dissolved primary $\gamma^{\prime}$ during solution treatment. Using a new quantitative analysis, we could clarify the contribution of each strengthening factor to the strength of TMW-4M3 at room temperature. The result clearly showed that differences in the solution temperature lead to a large influence on the contribution of the grain boundary, secondary $\gamma^{\prime}$ and tertiary $\gamma^{\prime}$ strengthening to the total $0.2 \%$ flow stress. Thus, it was found that understanding the evolution of the primary $\gamma^{\prime}$ during the solution-heat-treatment is a key to the optimization of microstructure combination in the disk superalloy, although the contribution of the precipitate is relatively small because of the large inter-particle spacing.

\section{References}

1. Roger C. Reed, The Superalloys Fundamental and Applications (New York, NY: Cambridge University Press, 2006), 217-242

2. Y.F. Gu, T. Fukuda, C.Y. Cui, H. Harada, A. Mitsuhashi, T. Yokokawa, J. Fujioka, Y. Koizumi and T. Kobayashi, "Comparison of Mechanical Properties of TMW Alloys, New Generation of Cast-and-Wrought Superalloys for Disk Applications", Metall. Mater. Trans. A, 40A (2009) 3047-3050.
3. Y.F. Gu, C. Cui, D. Ping, H. Harada, T. Fukuda, J. Fujioka, "Creep Behavior of New Kinds of Ni-Co-Base Superalloys", Mater. Sci. Eng. A, 510-511 (2009) 250-255.

4. R.W. Kozar, A. Suzuki, W.W. Milligan, J.J. Schirra, M.F. Savage, T.M. Pollock, "Strengthening Mechanism in Polycrystalline Multimodal Nickel-base Superalloys" Metal. Mater. Trans. A, 40 (2009) 1588-1603

5. H.Harada, Y.F. Gu, C.Y. Cui, M. Osawa, A. Sato, "HeatResistant Superalloy", European patent: EP1842934B1, 19/10/2011.

6. Y. Yuan, Y.F. Gu, C.Y. Cui T. Osada, T. Yokokawa and H. Harada, "A Novel Strategy for the Design of Advanced Engineering Alloys-Strengthening Turbine Disk Superalloys via Twinning Structures”, Adv. Engng. Mater., 13 (2011) 296.

7. Y. Yuan, Y.F. Gu, C.Y. Cui T. Osada, Z. Zhong, T. Tetsui, T. Yokokawa and H. Harada, "Influence of Co Content on Stacking Fault Energy in Ni-Co Base Disk Superalloys" J. Mater. Res, 26 (2011) 2833-2837.

8. M.P. Jackson, R.C. Reed, "Heat Treatment of UDIMET 720Li: The Effect of Microstructure on Properties", Mater. Sci. Eng. A, 259 (1999) 85-97.

9. Y. Ro, Y. Koizumi and H. Harada, "High Temperature Tensile Properties of A Series of Nickel-Base Superalloy on A $\gamma / \gamma^{\prime}$ Tie Line”, Meter. Sci. Eng., A223 (1997) 59-63.

10. K. Miyahara, N. Nagashima, S. Matsuoka, "Development and application of a combined atomic force microscopynanoindentation system with a silicon tip and a diamond indenter", Phil. Mag. A, 82 (2002) 2149-2160.

11. K. Miyahara, S. Matsuoka and T. Hayashi, "Nanoindentation as a strength probe - a study on the hardness dependence of indent size for fine-grained and coarse-grained ferritic steel" Metal. Mater. Trans. A, 32 (2001) 761-768.

12. N. Nagashima, S. Matsuoka, "Nanoscopic Strength Analysis of Work-Hardened L-Grade Austenite Stainless Steel, 316 (NG)", Mater. Trans., 47 (2006) 2326-2334.

13. T. Osada, N. Nagashima, Y.F. Gu, Y. Yuan, T. Yokokawa and H. Harada, "Factors Contributing to the Strength of A Polycrystalline Nickel-Cobalt Base Superalloy" Scripta Mater., 64 (2011) 892-895.

14. T. Osada, Y.F. Gu, T. Yokokawa, H. Harada, "Grain Growth Behaviors of A New Ni-Co Base Disk Superalloys During Solution Heat Treatment” J. Jap. Inst. Mater. , 74 (2010) 279-284. (In Japanese).

15. T. Osada, Y.F. Gu, T. Yokokawa, Y. Yuan, H. Harada, "A Kinetic Model for Grain Growth in A Polycrystalline Ni-Co Base Superalloy with $\gamma / \gamma^{\prime}$ Two-Phase", J. Jap. Inst. Mater., 74 (2010) 688-696. (In Japanese)

16. NRIM Fatigue data sheet, National Research Institute for Metals, MatNavi, http://smds.nims.go.jp/fatigue/index_en.html.

17. S. Matsuoka, "Relationship between $0.2 \%$ Proof Strenn and Vickers Hardness of Work-Hardened Low Carbone Austenaitic 
Stainless Steel, 316SS” Jap. Soc. Mech. Eng. A70 (2004) 15351541 (In Japanese)

18. E. Nembach, Particle Strengthening of Metals and Alloys, Wiley, New York, (1996) 253

19. S.Schanzer and E. Nembach, "The Critical Resolved Shear Stress of $\gamma^{\prime}$-Strengthened Nickel-Based Superalloys with $\gamma^{\prime}$ Volume Fraction Between 0.07 and 0.47", Acta Metall. Meter, 40 (1992) 803-1479.

20. N.J. Petch, "The Cleavage Strength of Polycrystal". Iron Steel Inst, 174 (1953) 25-28.

21. B. Reppich, "Some New Aspect Concerning Particle Hardening Mechanisms in $\gamma^{\prime}$-Precipitating Nickel-Base Alloys- I. Theoretical Concept", Acta Merall. 30 (1982) 87-94.

22. Y. Yuan, Y.F. Gu, T. Osada, Z.H. Zhong, T. Yokokawa, and H. Harada, "A New Method to Strengthen Turbine Disc Superalloys at Service Temperatures", Scripta Mater., 66 (2012) 884-889.

23. Y. Yuan, Y.F. Gu, T. Osada, Z.H. Zhong, T. Yokokawa, and H. Harada, "Deformation Mechanisms in a New Disc Superalloy at Low and Intermediate Temperatures", Scripta Mater., (Accepted) 